\title{
Sustainable Development Reporting Practices by Nigerian Banks
}

\author{
Oyewo Babajide Michael
}

ACA, ACTI, ACMA (UK), CGMA, Department of Accounting, Covenant University, Ota, Ogun State, Nigeria

Email: meetjidemichael@ymail.com

\section{Badejo Solomon Oluseye}

\author{
ACA, ACTI, Senior Tutor, Protrac Associate Limited, Lagos State, Nigeria
}

Email: koolseye@ymail.com

\section{Doi:10.5901/mjss.2014.v5n23p2535}

\begin{abstract}
Business activities could, in uncontrolled circumstances, produce unfortunate negative Environmental and Social (E\&S) impacts, necessitating the involvement of organizations in sustainability practices. In Nigeria, deposit money banks are few of the organizations that dedicate noticeable number of pages in their annual reports to reporting corporate social responsibility (CSR) activities. By our reckoning, knowing whether firm characteristics in any way affect the level of involvement in CSR, and whether the practice differ among banks, merit research attention, which is the focus of this paper. A checklist containing 30 items was developed to content-analyse the 2012 published annual reports of 12 selected publicly quoted banks for sustainability practice disclosures. It was observed that Nigerian banks were involved mostly in the social aspect of sustainability; sustainable solution practices among them were not significantly different though. Firm characteristics such as size and profitability were found not to affect sustainability practice.
\end{abstract}

Keywords: Corporate Social responsibility, Nigeria, sustainable development, Sustainability, Small and medium scale enterprises.

\section{Introduction}

\subsection{Background to the study}

Organizations exist as a subsystem of the society. It could happen that the undertakings of an entity - its human assets, physical assets, infrastructures (e.g. offices, branches, equipment), and engaged facilitators of its business activities and operations such as suppliers, contractors and third party service providers - could deliberately or accidentally cause damage to the environment and the society. To put it differently, business activities could, in uncontrolled circumstances, produce unfortunate negative Environmental and Social $(E \& S)$ impacts including air and water pollution; destruction of biodiversity and ecosystems; threats to human health and safety; violations of labour rights; displacement of livelihoods. It does make sense to give back to the society for this disturbance, necessitating sustainable development.

Writers in support of giving back to the society such as Miles (2012), Aguilera and Ganapathi (2007), Barbier, (2007), Cohen and Winn (2007) opined that the profit any organization makes represents the extent to which it exploits the society. As a result of the foregoing, it is intuitively appealing to give back to the society some part of the benefits derived through sustainability practices. Giving back to the society may not necessarily be monetary or materialistic. The process starts with conducting business operations in such a manner that the society is not damaged, deterioration minimized or the remediation of damage done is corrected in a timely fashion. Impacting lives directly through social investments is another way of doing it. Another perspective from which an organization can add value is to contribute to the economic development. The standpoint from which contributions can be made to the society gives rise to the sustainability perspectives which are: Environmental, social and economic.

Facing and addressing the threats posed by it is the responsibility of everybody in the society, after all everyone draws breathe in the society; but the extent to which one gets involved may differ depending on size, societal expectations, position occupied in the society and availability of resources.

Considering the enormous resources it takes to keep a society running, the tendency exists that one would think sustainability is the responsibility of government majorly and corporate organizations perceived as merely augmenting governmental efforts in the fight to create sustainability. The possibility also exists to conclude that sustainability is a big 
deal - a big business that requires a great deal, meant for big citizens (individual and corporate). We are of the opinion that it is everybody's responsibility. In order to unveil the mask, demystify the misconception and clarify the notion that capacity is needed to create sustainability, we have decided to research CSR practices of large-scale organizations to learn lessons for practice adoption and application.

We proceeded by studying CSR practice of one of the key sectors in the Nigerian economy considered to be comprising of large scale organizations- commercial banks. They are considered large because as at 2014, it takes a minimum capital base of N10billion for the floatation of regional commercial banking business, besides other requirements such as branch network coverage and huge running costs, public quotation and stringent regulations by governmental agencies. Most of the other organizations having national and international banking licenses have minimum capital base of N25billion and N50billion respectively.

\subsection{Statement of Research Problem}

A look at the published financial statements of companies show that there is a section specially dedicated to the reporting of sustainable development. Such section typically carries different headings such as 'corporate social responsibility report' and 'sustainability report' in different annual reports provide information about the corporate social responsibilities of organisations. In Nigeria, deposit money banks (DMB) are some of the few organisations that dedicate noticeable number of pages in their financials to report corporate social responsibility activities. The activities disclosed by the banks are heterogeneous. By our reckoning knowing on one hand whether firm characteristics in any way affect the involvement of banks in CSR, and on the other whether the practices significantly differ among the banks, merit research attention, because such understanding should provide an in-depth understanding as to why organisations participate in CSR.

\subsection{Research Questions}

By examining the sustainable development practices of banks in Nigeria, we should be able to make certain deductions to answer the following research questions:

(i) Do firm characteristics affect the sustainability practices of Nigerian Banks?

(ii) What sustainability perspective is predominantly pursued by Nigerian Banks?

(iii) Are there significant differences in the sustainability practices among Nigerian Banks?

\subsection{Research Hypotheses}

Two research hypotheses were conjectured for the study and are stated as follows:

\subsubsection{Hypothesis One}

$\mathrm{H}_{0}{ }^{1}$ : Firm characteristics do not influence the sustainable development practice of Nigerian Banks

This hypothesis is broken into two:

$\mathrm{H}_{0}$ 1.1: The size of a firm does not influence its Sustainable development practice

$\mathrm{H}_{0}$ 1.2: Profitability does not affect sustainable development practice of Nigerian Banks.

\subsubsection{Hypothesis Two}

$\mathrm{H}_{0} 2$ : Sustainability practices do not significantly differ among Nigerian commercial banks

\section{Literature Review}

\subsection{The concept of Sustainability}

Sustainability refers to the capacity to endure. Three pillars of sustainability has been identified such environmental, social and economic (Atkinson, 2009; Heal, 2009 Endress, 2005; Feenstra, 2002). Sustainable development is the utilization of resources to meet the economic, social and environmental needs of human, such that the interest of the present and future generation is served. Sustainability is about ensuring long-term business success while contributing towards economic and social development, a healthy environment and a stable society. It is about being able to deliver 
positive impact to society while protecting the communities and environment in which the business operates (Mary, 2008; Ratner, 2004; Dyllick and Hockerts, 2002).

There are connections among the three pillars of sustainability. Economic activities have social and environmental consequences. Social activities that directly impact human lives also extend to the economy and environment. It is popular for organizations to entrench their sustainability practices through the couching of corporate social responsibilities, which spells out their social, environmental and economic responsibilities and commitment. Environmental sustainability is aimed at interacting with the environment in such a manner that its elements are not damaged but preserved for future generations. Thus, environmental sustainability advocates that human being carry out their activities such that environmental resources used can be replenished as fast as possible. Economic sustainability is aimed at ensuring that the economy continues to operate such that it develops human lives financially. Social sustainability focuses on the preservation and impacting of human lives.

\subsection{Organisations and Sustainable development}

An organization that provides the basic needs of the society-economically, environmentally and socially-is expected to be continuously relevant. An organization that uses the total quality management approach will be focusing on improving quality. A learning organization also adapts itself to changes in the environment; changes in terms of the type of goods and services it offers the customers.

Sustainability is not simply a matter of minimizing environmental damage. It consists of three interlocking goals: environmental, economic, and social. Sustainability is aimed at raising the standard of living of people while reducing the negative environmental consequences of economic activity (Mary, 2008).

Economic sustainability ensures that resources are used in the best possible ways. If resources are economically, effectively and efficiently utilized by organisations, they are likely to provide long-term benefits. To create sustainability, learning is critical, because being innovative requires knowledge which is to be learnt in order to continuously improve.A learning organization will produce economic goods and services in new innovative ways without compromising quality. An organization that wants to create economic sustainability will be particular about quality and continuous improvement on qualities. The more qualitative a product or service is, the more economically sustainable the product will be (Cua, McKone, and Schroeder, 2001). Social sustainability focuses on areas such as: health, community development, human rights, cultural competence and human adaptation. Providing qualitative goods and services, through TQM, can be applied not only as a competitive strategy by organisations but also as a sustainable solution strategy. The Total Quality Management (TQM) programs is launched in an attempt to retain or regain competitiveness in order to ensure customers are satisfied because of increasing competition from around the world in this era of globalization. Quality could be improved from the perspective of the environment, the economy and the social life of people. Products and services rendered are expected to contribute to one or all of these areas to create and sustain sustainability.

Total Quality Management (TQM) is an integrative philosophy of management for continuously improving products and processes qualities. The creation of quality is the responsibility of every organization providing goods and services in the society. Creating and enhancing sustainability is also the responsibility of all forms of business-sole-proprietorship, partnership, private and public companies in the society. TQM incorporates the involvement of management, workforce, suppliers and customers in order to meet customers' expectations. For instance, in developing a sustainable product by a firm, customers' needs and specification will be required. When the product is also developed, feeds backs will be needed as to if the product designed and launched meet the needs of customers. A product will only be sustainable if it meets the economic and social needs of customers.

TQM practices contribute to sustainable development and it involves process management, supplier quality management, customer involvement, information and feedback, committed leadership, strategic planning, crossfunctional training, employee involvement.

By investing in the social, economic and environmental needs of the countries and communities where they conduct businesses, organisations can deepen goodwill while ensuring sustainable operations, by contributing to the improvement of the quality of life.

The existence of crisis portends that a problem exist requiring lasting solution(s). Providing sustainable solution to societal problem is a major way of managing crisis in the society. Consider for example crisis created by environmental pollution in the society. This crisis could be addressed through environmental sustainability by repairing the damage/pollution created in the environment. But the desire to further improve the environment will cause a firm to continuously seek ways of minimizing to the barest minimum the effects of environmental contamination and pollution. Better still, the firm may research and launch products that are environmentally friendly and will continuously improve the 
quality of the product through total quality management. The same scheme of reasoning could be applicable to social and economic sustainability. For example, a firm will keep improving the usefulness of a product to the users by improving the quality of the product to address quality issues or crisis that may arise because of changing environmental factors.

\subsection{Sustainable development practices by Nigerian Banks}

The Nigerian banking sector has been selected for study because banks in Nigeria are one of the few firms that report their involvement in sustainable developments in their published annual reports.

The review of annual reports of Nigerian banks show that the following are the commons sustainability practices pursued;

(a) Energy Saving Measures: Environmentally responsible practices involve identifying, assessing and seeking to reduce the direct and indirect environmental impact by being mindful of its carbon footprints and taking measures to neutralise and minimise its adverse impact on the environment, the reduction of energy consumption and lighting, and energy management.

(b) Waste Reduction \& Recycling: Continually promoting reduced paperless culture where employees are encouraged to use electronic communications, online approvals and other web- based applications, and to print documents only when required. Automation of document workflows, which minimizes paper usage, use of recycled biodegradable paper cash bags, paperless computing concepts which ensure that internally generated communication is handled electronically without recourse to paper printing. In Nigerian banks, cashless banking concepts have eliminated the use of paper and cheque books for certain categories of transactions resulting in huge paper savings, and the delivery of transaction documents electronically.

(c) Employee Relations: Creating a healthy, safe and fulfilling work environment that supports personal growth; encouraging individuality and instigates team spirit; staff training and personality development.

(d) Diversity: Promoting diverse workforce as a means of attracting top-flight talents; treating all employees fairly, not discriminating on the basis of gender, race, colour, nationality, religious belief or any other distinctive attribute; ensuring that under-represented groups continue to have access to available opportunities within the organisation.

(e) Financial Inclusion: Providing easy access to a broad range of financial products designed according to their needs and provided at affordable costs - this CSR measure is peculiar to banks because they primarily exist to provide financial services; promoting financial inclusion is essential to building a sustainable, vibrant and robust financial system; financial literacy —a state in which all economic agents or bankable public know, understand and develop the ability to evaluate and assess financial products and services or transact in financial markets; taking banking products to underdeveloped areas of the country.

(f) Health \& Safety: Ensuring the health and safety of employees, customers and other stakeholders; constantly seeking to identify and reduce the potential for accidents or injuries in all operations; training and communication of health and safety matters; fostering awareness on health issues, providing suitable health infrastructure and providing financial assistance for the treatment and management of health issues; embarking on several initiatives that aim to reduce new infections and mitigating the effects of current infections in sub-Saharan Africa; taking steps to minimize workplace HIV discrimination and stigmatization among employees.

(g) Supply Chain Management: Working in active partnership with its suppliers, to help them manage their own social and environmental risks; committed to treating its suppliers with respect, especially in areas such as contract terms and conditions and payment terms.

(h) Active Engagements and Collaborative Partnerships: Working with other organizations and multilateral institutions to help raise awareness of environmental and social issues; contributing to the wider public debate on environmental and social sustainability.

(i) Reporting: Reporting on corporate social responsibility is also a sustainability practice, since there is currently no regulation mandatorily requiring the furnishing of information on CSR; reporting on CSR is therefore considered a demonstration of strong respect and recognition of the relevance of the society to its business place.

(j) Capacity Building: Developing individual institutional and sector capacity necessary to identify asses and manage the environmental and social risks and opportunities associated with business activities and operations.

(k) Addressing climatic and ecological changes: Recognizing climate change as a serious global challenge and 
that climate-related impacts may impede economic and social well-being and development efforts and rising to meet the challenge; the reduction of greenhouse gas (GHG) emissions; engaging in innovative investments and advisory services to support climate-friendly solutions; support for low-carbon economic development.

(I) Human rights: Avoiding infringement on the human rights of others and addressing adverse human rights concerns.

(m) Community investment programmes/projects: Getting involved within communities in which the organization operates; providing basic needs, rehabilitation of hospitals, renovation of schools, equipment of craft workshops, donation of books to school libraries and construction/equipment of school computer laboratories; reducing poverty, improving health and increasing long-term employment through internal community help initiative.

(n) Support for educational advancement: Providing infrastructure, supporting research and providing learning support materials, creating an environment conducive to learning, provision of scholarships and donating the construction of education buildings

(o) Entrepreneurial training: Building entrepreneurial capacity of aspiring entrepreneurs through different programmes, such as training, and entrepreneurial radio talk shows.

(p) Disability support: Providing financial assistance to disabled persons e.g. deaf and dumb, destitute, and mentally challenged persons.

(q) Security support and crime fighting: Recognising the connection between the security of life and properties and economic empowerment and taking steps to augment the government's activities in this area; promoting security awareness, crime prevention and fighting initiatives; provision of security vans for law enforcement operatives; contributing to security trust funds.

(r) Employee volunteering: Encouraging employees to give their time, resources, skills and energy to causes they care about and initiatives approved and supported by the organization; offering employees the opportunity to share their time and resources with the less privileged.

\subsection{Theoretical framework}

This research work is premised on the stakeholders' theory. The stakeholders theory posits that the organization exist not primarily for itself and owners but also for the benefit of the society. Moral and value considerations are as important as profitability matters in a business (Mansell, 2013 Miles, 2012; Aguilera and Ganapathi, 2007). Recognizing that there are other stakeholders that have interest in the organization has implications for business policy and strategies, such as striking a balance between sustainability and profitability. Czyzewski and Hull (1991) submitted that an organization that places too much concern on profitability with little or no consideration for sustainability may not remain competitive in the long run because, for organizations to remain going concerns, maintaining relevance by solving the environmental, social and economic problems of the society becomes sacrosanct.

The stakeholders' theory, in the context of this research, posits that organisations engaging in corporate social responsibility or sustainable development practices are doing so, as a way of giving back to the society. They are not just concerned about the owners of the organisations (shareholders) but also other stakeholders such as the government and their host community. It is this realisation that therefore spurs them to get involved in sustainable developments through corporate social responsibility activities.

An organisation contributing to sustainability is likely to remain profitable eventually, because sustainability activities are expected to portray a good image of the organisation, such as to attract customers' patronage and investors' interest, incidentally leading to favourable financial performance. For example, an organization that promotes environmental sustainability by remedying environmental damages caused by the release of toxic substance, emission, waste or pollution into the environment as a result of its operations will be seen as being environmental-friendly. Also an organization that promotes social sustainability through the delivery of corporate social responsibilities is likely to earn the goodwill of the society. Firms enhancing economic sustainability by providing goods and services that meet the needs of the society will equally enjoy public patronage. Either a firm engages in one or all of the three sustainability approaches environmental, social and economic - such a firm will have a good public image, which will favour it as per patronage by the public, thereby eventually leading to profitability (Miles, 2012; Aguilera and Ganapathi, 2007).

Therefore the understanding that by giving to the society, the company will benefit more, should naturally motivate any rational individual, group, or organization to intrinsically and willingly give to the society. 


\section{Methods}

\subsection{Research instrument}

A checklist was developed by the researcher as the research instrument to measure Sustainability practice disclosures for the study. In an attempt to make the checklist comprehensive and definitive and as much as possible inclusive, relevant literatures were reviewed on one hand, and various sustainable solution practice (SSP) items generally disclosed in published annual financial reports of companies were identified on the other hand. This culminated to the identification of thirty (30) sustainable solution variables that featured in the checklist. The parameters were categorized into four broad classes of sustainability as follows: economic, social, environmental and 'general'. For the purpose of the research, an item is considered 'Economic' if it has direct financial impact on the economy. Social if it directly affects people and their livelihood, 'Environmental' if the SSP directly affects the physical environment.

The 'general' refers to the sustainability practice which cuts across and as such could not be categorically and exclusively classified into any of the other three SSP.

Table 1: Sustainable solution practice checklist

\begin{tabular}{|c|c|c|}
\hline $\mathrm{S} / \mathrm{N}$ & SSP item & Categorization \\
\hline 1 & Lending to organizations that help improve environment \& society (Sustainable Lending) & Economic \\
\hline 2 & Integrating environmental impact considerations into business decisions across the organization & General \\
\hline 3 & Energy Saving Measures & Environmental \\
\hline 4 & Waste Reduction \& Recycling & Environmental \\
\hline 5 & Employee Relations \& training & Social \\
\hline 6 & Diversity & Social \\
\hline 7 & Financial Inclusion & Economic \\
\hline 8 & Health \& Safety & Social \\
\hline 9 & Active Engagements in collaboration in promoting environmental awareness & Environmental \\
\hline 10 & Minimising or offsetting negative impacts of Operations on the environment/local community & Environmental \\
\hline 11 & Respect for human rights & Social \\
\hline 12 & Women's economic empowerment through gender inclusive workplace culture & Social \\
\hline 13 & Promoting Environmental \& social governance practice & Environmental \\
\hline 14 & Capacity Building & Social \\
\hline 15 & Sustainability reporting practice & General \\
\hline 16 & Delivery of quality service & Social \\
\hline 17 & Addressing climatic and ecological changes & Environmental \\
\hline 18 & Financial support for SMEs & Economic \\
\hline 19 & Community investment programmes & Social \\
\hline 20 & Disability support & Social \\
\hline 21 & support for educational advancement & Social \\
\hline 22 & Support for the less-privileged & Social \\
\hline 23 & Offering of financial services & Economical \\
\hline 24 & Disclosure on amount expended on CSR & General \\
\hline 25 & Security support & Social \\
\hline 26 & Employee volunteering scheme (EVS) & General \\
\hline 27 & Policy on sustainability & General \\
\hline 28 & Compliance with local and global best practices and ensuring adherence to environmental, social, cultural and economic principles & General \\
\hline 29 & Sports support \& development. & Social \\
\hline 30 & Partnership with suppliers to manage their own social and environmental risks & Social \\
\hline
\end{tabular}

The published accounts of sample companies were scrutinized for each of the items for disclosure: score ' 1 ' is assigned if any of the parameters is found while score ' 0 ' is assigned if an item is not found. The sustainable solution practice index (SSPI) was thereafter derived for each company and was obtained as follows:

SSPI= Total score obtained by individual firm x 100/ Total score obtainable.

In evaluating and ranking the extent of SSP disclosure by Nigerian banks, a guide for the interpretation of SSPI score is provided as in table 2 . 
Table 2: SSPI score ranking and interpretation guide

\begin{tabular}{|c|l|c|}
\hline Range of score for SSP index & Interpretation & Ranking of code assigned \\
\hline $100-70$ & Substantial & 2 \\
\hline $69-60$ & High & 3 \\
\hline $59-50$ & Moderate & 4 \\
\hline $49-40$ & Low & 5 \\
\hline $39-0$ & Very Low & 2 \\
\hline
\end{tabular}

\subsection{Study population, sample and sampling technique}

The population of the study is the publicly quoted commercial banks in Nigeria.

Samples were selected based on the existence of a stand-alone report (sections of annual reports specifically dedicated to SSP and/ or CSR) on sustainability \& corporate social responsibility in the year 2012 annual reports. On the basis of these criteria, 12 banks emerged and were selected for content analyses of annual reports and accounts, for the year 2012. Year 2012 was selected as the basis period because the information disclosed in the financials for this year were expected to be reflective and indicative of the most recent SSP of sample firms.

In no particular order, the banks that emerged for study were: Zenith bank PLC, Guaranty Trust Bank (GT Bank) PLC, Access Bank PLC, Diamond Bank PLC, First Bank PLC, Skye Bank PLC, Union Bank PLC, First City Monument Bank (FCMB) PLC, Fidelity Bank PLC,UBA PLC,WEMA bank Plc. and Ecobank PLC.

The banks were further classified into three classes, based on the CBN licensing of banks in November 2010 in the category of regional, national and international banks with minimum capital base of N10billion, N25billion and N50billion respectively.

\subsection{Data analysis method}

Correlation analysis was used to examine relationships between variables. The Kolmogorov-Smirnov Test (K-S statistics) was used to test for normality. Analysis of Variance (ANOVA) was used to test for mean difference among the study groups. The Statistical package for social sciences software (SPSS version 17) was used for all the statistical computations. Decision as per acceptance or rejection of hypotheses will be made based on $5 \%$ significance level.

\subsection{Reliability of data}

Data were sourced from the published annual reports and accounts of companies. The knowledge that the published reports were audited by external auditors and approved by the Securities and Exchange Commission (SEC), the Nigerian Stock Exchange (NSE) and the Central Bank of Nigeria (CBN) provides assurance to a large extent as to the credibility and the reliability of the data.

\section{Analyses and Discussions}

\subsection{Result presentation}

This section presents the SSP index of each company and the results of statistical procedures performed 
Table 3: Sustainable solution practice in the Banking Sector

\begin{tabular}{|c|l|c|c|c|c|c|c|l|c|}
\hline S/N & Firm & Economic & Social & Environmental & General & SSP score & SSP index & Interpretation & Ranking \\
\hline 1 & Zenith & 4 & 6 & 3 & 2 & 15 & 50.00 & Moderate & $6^{\text {th }}$ \\
\hline 2 & GTbank & 5 & 6 & 2 & 1 & 14 & 46.67 & Low & $7^{\text {th }}$ \\
\hline 3 & Access & 4 & 13 & 1 & 2 & 20 & 66.67 & High & $2^{\text {nd }}$ \\
\hline 4 & Diamond & 3 & 11 & 2 & 1 & 17 & 56.67 & Moderate & $4^{\text {th }}$ \\
\hline 5 & First bank & 4 & 14 & 0 & 3 & 21 & 70.00 & Substantial & $1^{\text {st }}$ \\
\hline 6 & Skye & 2 & 11 & 4 & 3 & 20 & 66.67 & High & $2^{\text {nd }}$ \\
\hline 7 & Unionbank & 1 & 9 & 1 & 2 & 13 & 43.33 & Low & $8^{\text {th }}$ \\
\hline 8 & FCMB & 2 & 7 & 6 & 3 & 18 & 60.00 & High & $3^{\text {rd }}$ \\
\hline 9 & Fidelity & 2 & 8 & 5 & 5 & 20 & 66.67 & High & $2^{\text {nd }}$ \\
\hline 10 & UBA & 2 & 6 & 1 & 1 & 10 & 33.33 & Very Low & $9^{\text {th }}$ \\
\hline 11 & WEMA & 2 & 6 & 3 & 5 & 16 & 53.33 & Moderate & $5^{\text {th }}$ \\
\hline 12 & Ecobank & 3 & 9 & 5 & 3 & 20 & 66.67 & High & $2^{\text {nd }}$ \\
\hline & Total & 34 & 106 & 33 & 31 & 204 & & & \\
\hline
\end{tabular}

Results in table 3 shows that the SSP of Nigerian banks differ as a result of the differences in score. First Bank, had the highest SSP index of 70.00, considered to be substantial. However, the score for first bank under environmental sustainability was zero because as a matter of policy, it stated in its sustainability report that its corporate social initiatives were conducted to focus on education, economic development and health \& welfare.

The disclosure by other banks such as Access bank, Skye bank, Fidelity bank and Ecobank was considered high. There are currently no accounting standards or legislation in Nigeria on Sustainability reporting, as disclosures are voluntary. It is against this backdrop we consider that a score in the range of 60 to 69 is high. Other banks scored between 60.00 and 33.33. Just as there is no legislation or accounting standards on CSR, organisations and individuals can voluntarily adopt any sustainable development practice, as matter of social responsibility, as can be seen from publicly quoted companies rendering sustainable development support voluntarily.

Result also shows that Nigerian banks were involved mostly in the social aspect of sustainability, which had a score of 106 over the 204 total ((representing 52\%). This is followed by economic sustainability with a score of 34 (16.6\%). Environmental sustainability was had a score of $33(16.1 \%)$ and the 'general' sustainability strategy which cut across the three typical SSP scored 31 (15.1\%). Overall, the four sustainability perspectives were well represented. Following the lead of sustainability practice by banks, SMEs have a range of activity opportunities to participate in SSP.

\subsection{Test of Hypotheses}

$\mathrm{H}_{0}$ 1.1: The size of a firm does not influence its Sustainable development practice

Table 4: Correlation between Firms size \& SSP

\begin{tabular}{|c|c|c|c|}
\hline & & EQUITY & Market Capitalization \\
\hline \multirow{3}{*}{ SSPINDEX } & Pearson Correlation & .133 & .184 \\
\cline { 2 - 4 } & Sig. (2-tailed) & .680 & .566 \\
\cline { 2 - 4 } & $\mathrm{N}$ & 12 & 12 \\
\hline
\end{tabular}

Decision: In table 4, since $p>0.05$, accept $\mathrm{H}_{0}$ and conclude that the size of a firm does not influence its Sustainable development practice

Two proxies were used to measure the construct 'firm's size'. The SSPI was correlated with each of equity capital and market capitalization to examine if there is any significant relationship. The $p$ value of equity capital and market capitalization when correlated with SSP is greater than 5\% significance level. Thus, we accept the null hypothesis and conclude that there is no significant relationship between size of an organization and its decision to engage in CSR. This suggests that participating in corporate social responsibility is not dependent on the size of the organization. For example, WEMA bank that is a regional bank had 53.33 SSPI score; it was still higher than some internationally-licensed banks such as Zenith bank (50), GT Bank (46.67), Union bank (43.33) and UBA (33.33). Besides, UBA had the lowest score of 33.33 despite its size in the financial service industry in comparison to other banks. Premised on the foregoing analysis, we conclude that any businesses, whatever its form, can participate in CSR. 
$\mathrm{H}_{0}$ 1.2: Profitability does not affect Sustainable development practice of Nigerian Banks.

Table 5: Correlation between Firms profitability \& SSP

\begin{tabular}{|c|c|c|c|c|}
\hline & & PBIT & PAT & Basic EPS \\
\hline \multirow{3}{*}{ SSPINDEX } & Pearson Correlation & .250 & .288 & .089 \\
\cline { 2 - 5 } & Sig. (2-tailed) & .434 & .365 & .784 \\
\cline { 2 - 5 } & $\mathrm{N}$ & 12 & 12 & 12 \\
\hline
\end{tabular}

Decision: In table 5, since $p>0.05$, accept $\mathrm{H}_{0}$ and conclude that Profitability does not significantly affect Sustainable development practice of Nigerian Banks.

Three proxies were used to measure firms profitability-PBIT (operating profit), profit after tax (PAT) and the basic EPS. The relationship between the SSPI and each of the three measures was not statistically significant. The extent to which a company makes profit is not expected to influence its CSR philosophy. Engaging in CSR is more of a decision to give back to the society than to profit-off the society such that if there is no profit, there will be no support for sustaining the environment.

Other organisations can also take a cue from this deduction. Engaging in CSR should be more of a policy than the desire to make profit from the society (although this should accrue eventually). It is only in the interest of businesses that the society continues to be sustained as the going concern of the company is dependent on the existence of the society: the business is a subsystem of the society. The realization of this is important for the improvement of attitude towards sustainability.

$\mathrm{H}_{0} 2$ : Sustainability practices do not significantly differ among Nigerian commercial banks

\subsection{Test for normality}

In deciding as to whether to use a parametric or non-parametric statistics, we examine the normality of the independent variable distribution by conducting a normality test using the Kolmogorov-Smirnov test. A Kolmogorov-Smirnov test with $p$ $>.05$ tells us that distribution of the sample is not significantly different from a normal distribution, but if however, the result is opposite i. e. $p<.05$, that means the distribution is non-normal.

Table 6: One-Sample Kolmogorov-Smirnov Test

\begin{tabular}{|l|l|c|}
\hline \multicolumn{2}{|c|}{$\mathrm{N}$} & SSPINDEX \\
\hline \multirow{2}{*}{ Normal Parametersa,b } & & 12 \\
\hline \multirow{3}{*}{ Most Extreme Differences } & Mean & 56.6667 \\
\cline { 2 - 3 } & Std. Deviation & 11.54701 \\
\hline Kolmogorov-Smirnov Z & Absolute & .223 \\
\cline { 2 - 3 } & Positive & .124 \\
\cline { 2 - 3 } & Negative & .223 \\
\hline Asymp. Sig. (2-tailed) & .774 \\
\hline a. Test distribution is Normal. & .587 \\
\hline b. Calculated from data. & \\
\hline
\end{tabular}

Since the distribution is normal, we therefore proceed to test the hypothesis using the ANOVA parametric statistics.

Table 7: ANOVA test result for hypothesis 3

\begin{tabular}{|c|c|c|c|c|c|}
\hline \multicolumn{6}{|c|}{ SSPINDEX } \\
\hline & Sum of Squares & $\mathrm{df}$ & Mean Square & $F$ & Sig. \\
\hline Between Groups & 115.556 & 2 & 57.778 & .385 & .691 \\
\hline Within Groups & 1351.111 & 9 & 150.123 & & \\
\hline Total & 1466.667 & 11 & & & \\
\hline
\end{tabular}

Decision: In table 7 , since $p>0.05$, we accept $\mathrm{H}_{0}$ and conclude that Sustainability practices do not significantly differ among Nigerian commercial banks

Table 7 shows the result of the hypothesis test that sustainable solution practices does not significantly differ among Nigerian commercial banks. Although, there are differences in sustainable development practices among Nigerian 
banks, the difference is considered not statistically significant at $5 \%$. The standard deviation for SSPI is $3.39 \%$, which is considered low, thereby further corroborating the acceptability of the hypothesis. As for SMEs, the result of the hypothesis indicates that organizations (small, medium and large) can participate in CSR at any level and in any way. Size does not determine or limit the type of CSR that can be participated in.

\section{Conclusion and Recommendations}

The paper examines current sustainability practices by large scale organizations using banks as basis. Continuous improvement through learning and total quality management help organizations create value and bring about sustainable development-environmentally, economically and socially. It was observed that Nigerian commercial banks participated more in social sustainability; participation in the other sustainability type was also noticeable though.

Results showed that CSR is not dependent on size or extent to which organizations make profit. Also, despite the difference in size of banks, there are empirical evidences that the sustainable solution practice among them is not significantly and statistically different. This suggests that sustainable development is a matter of organisational policy than firm characteristics: the reckoning that organizations exist because the society exists and as such giving back to the society to acknowledge this fact explains organisations' involvement in social responsibilities.

\section{Recommendations}

Sustainability is not only the responsibility of big corporate entities. Small and Medium sized organisations and individuals too can contribute to sustainability at their own level. If a business cannot participate in big CSR projects on the account of its size or resource requirements, it could collaborate with other firms or individuals or partner with specialized agencies specifically set-up to cater for environmental, social or economic sustainability. From content-analysis, it was observed that employee volunteering scheme (EVS) is one of the most common sustainable solution practice (SSP) by employees, implying that involvement in some social responsibility activities is entirely up to the employees in organizations; policies formulated by organisations to promote such activities where the employees work could motivate them to get involved though. This deduction provides some useful insights that individuals can also do their bit in CSR, no matter how seemingly small, to make the society a better place. Individuals and organizations can give back to the society at any level by engaging in the variety of CSR practices available.

\section{References}

Ayong Le Kama, A. D. (2001). Sustainable growth renewable resources, and pollution. Journal of Economic Dynamics and Control 25 (12): 1911-1918

Atkinson, G.,Dietz, S and E. Neumayer (2009). Handbook of Sustainable Development. Edward Elgar Publishing

Barbier, E. (2007) Natural Resources and Economic Development, Cambridge University Press

Cua, K. O., K. E. McKone, and R. G. Schroeder.(2001) Relationships between implementation of TQM, JIT, and TPM and manufacturing performance. Journal of Operations Management, 19, 675-694.

Cohen, B. and Winn, M.(2007). Market imperfections, opportunity and sustainable entrepreneurship. Journal of Business Venturing, 22(1): 29-49.

Czyzewski, A. B. and Hull R. P. (1991). Improving Profitability with Life cycle Costing. Journal of Cost Management (summer): 99

Dyllick, T. and Hockerts, K. (2002). Beyond the business case for corporate sustainability. Business Strategy and the Environment, 11(2): 130-141

Edwards, A.R., and McKibben B.(2010). Thriving Beyond Sustainability: Pathways to a Resilient Society. New Society Publishers

Endress, L.; Roumasset, J.; Zhou, T. (2005). Sustainable Growth with Environmental Spillovers. Journal of Economic Behaviour and Organization 58 (4): 527-547

Feenstra, G. (2002). Creating Space for Sustainable Food Systems: Lessons from the Field. Agriculture and Human Values. 19 (2): $99-106$

Heal, G. (2009). Climate Economics: A Meta-Review and Some Suggestions for Future Research. Review of Environmental Economics and Policy 3 (1): 4-21

Hamilton, K.; Clemens, M. (1999). Genuine savings rates in developing countries. World Bank Econ Review 13 (2)

Mansell, S. (2013) Capitalism, Corporations and the Social Contract: A Critique of Stakeholder Theory. Cambridge: Cambridge University Press

Mary C. (2008). What Sustainability Should Mean. Challenge, 51, (2): 27-39.

Miles, S. (2012). Stakeholders: essentially contested or just confused? Journal of Business Ethics 108(3): 285-298.

Ratner, B.D. (2004). Sustainability as a Dialogue of Values: Challenges to the Sociology of Development. Sociological Inquiry 74(1): 50-69

White, F; Stallones, L; Last, J. (2013). Global Public Health: Ecological Foundations. Oxford University Press 